Revista Brasileira de Agricultura Irrigada v.12, nº.3, p. 2632 - 2643, 2018

ISSN 1982-7679 (On-line)

Fortaleza, CE, INOVAGRI - http://www.inovagri.org.br

DOI: $10.7127 /$ rbai.v12n300783

Protocolo 783.18 - 14/10/2017 Aprovado em 30/05/2018

\title{
CRESCIMENTO DE MUDAS DE ACEROLEIRA “CMI 102” IRRIGADAS COM ÁGUAS SALINIZADAS E ADUBAÇÃO NITROGENADA
}

Francisco Wesley Alves Pinheiro ${ }^{1}$, Reginaldo Gomes Nobre ${ }^{2}$, Leandro de Pádua Souza $^{1}$, Luana Lucas de Sá Almeida ${ }^{1}$, Edinete Nunes de Melo ${ }^{3}$, Benedito Ferreira Bonifácio $^{4}$

\section{RESUMO}

A exploração agrícola na região semiárida do nordeste brasileira fica na dependência da utilização da irrigação para garantir a produção das culturas; entretanto partes das águas utilizadas apresentam grandes concentrações de sais sendo necessário o desenvolvimento de tecnologias que possibilitem seu uso na agricultura. Desta forma, objetivou-se, avaliar o efeito de distintos níveis salinos da água de irrigação associado a doses crescentes de adubação nitrogenada sobre o crescimento de mudas de aceroleira “CMI102”. O experimento foi conduzido em um Neossolo flúvico em casa de vegetação no município de Pombal-PB. Adotou-se delineamento de blocos casualizados no esquema fatorial $5 \mathrm{x}$ 4 , com duas plantas por parcela e quatro repetições, sendo os tratamentos compostos por cinco níveis de condutividade elétrica da água de irrigação - CEa (0,3; 1,3; 2,3; 3,3 e 4,3 $\mathrm{dS} \mathrm{m}^{-1}$ ) e quatro doses de nitrogênio $(70 ; 100 ; 130$ e $160 \%$ da dose recomendada de $\mathrm{N}$ )

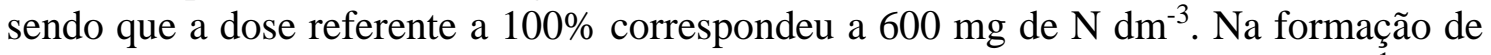
mudas de aceroleira “CMI 102”, pode ser utilizada água com CEa de 1,88 dS mº, pois promove redução média aceitável de $10 \%$ no crescimento das mudas. O aumento na salinidade da água de irrigação reduz o crescimento de mudas, principalmente aos 135 dias após a emergência. Doses de adubação nitrogenada de $420 \mathrm{mg}$ de $\mathrm{N} \mathrm{dm}^{-3}$ (70\% da dose recomendada) proporcionou aumento do diâmetro do caule em interação com 0 aumento da salinidade da água de irrigação.

Palavras-chave: produção de mudas, água salina, doses de nitrogênio.

\section{GROWTH OF "CMI 102" CHERRY TREES IRRIGATED WITH SALINIZED WATERS AND NITROGEN FERTILIZATION}

\footnotetext{
${ }^{1}$ Doutorando em Engenharia Agrícola, UFCG, e-mail: wesley.ce@hotmail.com; engenheiropadua@hotmail.com; luana_lucas_15@hotmail.com

2 Doutor em Engenharia Agrícola, Professor Adjunto, UFCG, e-mail: rgomesnobre@yahoo.com.br

${ }^{3}$ Mestre em Horticultura Tropical, UFCG, e-mail:ednetmello@gmail.com

${ }^{4}$ Mestre em Sistemas Agroindustriais, UFCG, e-mail: benedito_agronomo@hotmail.com
} 


\begin{abstract}
Agricultural exploitation in the semi-arid region of northeastern Brazil is dependent on the use of irrigation to guarantee crop production; however, parts of the waters used have large concentrations of salts and the development of technologies that allow their use in agriculture is necessary. The objective of this study was to evaluate the effect of different saline levels of irrigation water associated to increasing doses of nitrogen fertilization on the growth of "CMI102" saplings. The experiment was conducted in a flavic Neosol under greenhouse conditions in the municipality of Pombal - PB. A randomized complete block design was used in the $5 \times 4$ factorial scheme, with two plants per plot and four replications, and the treatments were composed of five levels of electrical conductivity of the irrigation water - CEa $\left(0.3,1.3,2,3\right.$, and $\left.4.3 \mathrm{dS} \mathrm{m}^{-1}\right)$ and four doses of nitrogen (70, 100,130 and $160 \%$ of the recommended dose of $\mathrm{N}$ ), the dose corresponding to $100 \%$ corresponded to $600 \mathrm{mg}$ of $\mathrm{N} \mathrm{dm}^{-3}$. In the formation of "CMI 102" seedlings, water with CEa of $1.88 \mathrm{dS} \mathrm{m}^{-1}$ can be used, as it promotes an acceptable average reduction of $10 \%$ in seedlings growth. The increase in the salinity of the irrigation water reduces the growth of seedlings, mainly to 135 days after the emergency. Doses of nitrogen fertilization of $420 \mathrm{mg}$ of $\mathrm{N} \mathrm{dm}^{-3}$ (70\% of recommended dose) provided an increase in stem diameter in interaction with the increased salinity of the irrigation water.
\end{abstract}

Keywords: production of seedlings, saline water, nitrogen doses.

\section{INTRODUÇÃO}

A acerola (Malphigia emarginata D.C) é uma planta frutífera originada das Antilhas, norte da América do Sul e América Central (BRUNINI et al., 2007). É uma fruteira que desenvolve-se bem em clima tropical e subtropical, podendo ser uma alternativa de renda para o produtor rural. No Brasil, a principal região produtora é a Nordeste, com 64\% da área cultivada no pais, correspondendo a uma produção média de $15.360 \mathrm{~kg} \mathrm{ha}^{-1} \mathrm{ano}^{-1}$ (ADRIANO et al., 2011; ESASHIKA et al., 2013). Apesar das boas perspectivas para o cultivo da aceroleira, o semiárido do Nordeste brasileiro apresenta riscos para o seu cultivo, devido à escassez dos recursos hídricos em aspectos quantitativos e qualitativos. Além disso, as fontes hídricas desta região, comumente, apresentam elevadas concentrações de sais, especialmente o sódio e cloro (PÁDUA et al., 2017).

Esta escassez hídrica afeta gravemente a população ocasionando grandes perdas sociais e econômicas, refletidas na diminuição da capacidade produtiva das áreas agrícolas acentuando o desemprego, reduzindo a concentração de renda e aumentando o empobrecimento de um contingente significativo da população (ALVES et al., 2011). Desta forma, a prática da irrigação se torna imprescindível para se garantir a produção agrícola com segurança e, nesta perspectiva, deve-se, também, ressaltar o fato de que a qualidade da água para irrigação nesta região apresenta grande variabilidade, tanto em termos geográficos como ao longo do ano (BEZERRA et al., 2010).

Dentre as características que determinam a qualidade da água para a irrigação, a concentração de sais solúveis ou salinidade é um dos principais fatores limitantes ao crescimento e desenvolvimento de algumas culturas (LACERDA et al., 2011). Tal situação promove alterações nas funções fisiológicas e bioquímicas dos vegetais, ocasionando redução na absorção e transporte dos elementos minerais essenciais, limitando o desenvolvimento do vegetal (NOBRE et al., 2013).

Dentre as alternativas para redução dos efeitos nocivos dos sais da água de irrigação às plantas, o fornecimento adequado de determinados adubos ao solo tem evidenciado ação positiva, entre os macronutrientes exigidos pelas plantas, o nitrogênio estar entre os principais, e quando aplicado em dose 
adequada eleva teor de clorofila nas folhas (ROZANE et al., 2007), fato que está relacionado às funções do $\mathrm{N}$ no metabolismo do vegetal, participando como constituinte da molécula de clorofila, ácidos nucléicos, aminoácidos e proteínas. Conforme Blanco et al. (2008) a adubação nitrogenada reduz os efeitos prejudiciais em certa extensão de salinidade da água e do solo, por favorecer o aumento da absorção de $\mathrm{NO}_{3}$ - em relação ao $\mathrm{Cl}^{-}$ , reduzindo a relação $\mathrm{Cl} / \mathrm{N}$ nas plantas. Outrossim, o acúmulo desses solutos orgânicos eleva a capacidade de ajustamento osmótico das plantas à salinidade, e aumenta a tolerância das culturas ao estresse salino e hídrico (SILVA et al., 2008).

Desta forma, objetivou-se com o trabalho, avaliar o efeito de distintos níveis salinos da água de irrigação associado a doses crescentes de adubação nitrogenada sobre o crescimento de mudas de aceroleira “CMI102”.

\section{MATERIAL E MÉTODOS}

O experimento foi conduzido de março a agosto de 2016, em condições de ambiente protegido (casa de vegetação) do Centro de Ciências e Tecnologia Agroalimentar da Universidade Federal de Campina Grande, Campus de Pombal-PB, cuja coordenada geográfica de 6048'16” $\mathrm{S}, 37^{\circ} 49^{\prime} 15^{\prime}$ " O e altitude média de $144 \mathrm{~m}$.

O delineamento experimental utilizado foi em blocos inteiramente casualizados em esquema fatorial $5 \times 4$, com quatro repetições e duas plantas por parcela, cujos tratamentos consistiram de diferentes níveis de condutividades elétricas da água de irrigação CEa $\left(0,3 ; 1,3 ; 2,3 ; 3,3\right.$ e 4,3 dS m$\left.{ }^{-1}\right)$, associado a doses de adubação nitrogenada (70; 100; 130 e $160 \%$ da dose recomendada de N). A dose referente a $100 \%$ correspondeu a $600 \mathrm{mg}$ de $\mathrm{N}$ $\mathrm{dm}^{-3}$ (FERREIRA et al., 2014).

As águas de diferentes salinidades foram preparadas mediante a adição do cloreto de sódio $(\mathrm{NaCl})$, de cálcio $\left(\mathrm{CaCl}_{2} 2 \mathrm{H}_{2} \mathrm{O}\right)$ e magnésio $\left(\mathrm{MgCl}_{2} .6 \mathrm{H}_{2} \mathrm{O}\right)$ na água de abastecimento (CEa de 0,3 dS $\mathrm{m}^{-1}$ ), na proporção de 7:2:1, relação esta predominante nas principais fontes de água disponíveis para irrigação no Nordeste brasileiro obedecendose a relação entre CEa e a concentração dos sais (mmolc $\mathrm{L}^{-1}=$ CE x 10) (MEDEIROS, 1992).

Para a obtenção das mudas foram utilizadas sacolas plásticas que apresentavam as seguintes dimensões de $25 \mathrm{~cm}$ de altura e 13 cm de diâmetro e com capacidade para 1150 $\mathrm{mL}$; estas possuíam furos na parte inferior para permitir a livre drenagem da água. No preenchimento das sacolas foi utilizado substrato composto de Neossolo flúvico + areia + esterco bovino respectivamente, na proporção de 82, 15 e 3\%. As sacolas foram acomodadas em bancadas metálicas (cantoneiras), a uma altura de $0,8 \mathrm{~m}$ do solo. $\mathrm{O}$ semeio ocorreu na profundidade de $0,5 \mathrm{~cm}$ utilizando-se de forma equidistante, cinco sementes por sacola.

As características físicas e químicas do solo utilizado na pesquisa (Tabela 1), foram obtidas conforme Claessen (1997) e analisadas no Laboratório de Solo e nutrição de Planta do CCTA/UFCG.

Tabela 1. Características físicas e químicas do substrato utilizado no experimento

\begin{tabular}{|c|c|c|c|c|c|c|c|c|c|}
\hline \multirow{2}{*}{\multicolumn{2}{|c|}{$\begin{array}{c}\text { Classificação } \\
\text { textural } \\
1 \\
\end{array}$}} & \multirow{2}{*}{$\begin{array}{c}\text { Densidade } \\
\text { aparente } \\
\mathrm{g} \mathrm{cm}^{-3} \\
\end{array}$} & \multirow{2}{*}{$\begin{array}{c}\text { Porosidade } \\
\text { total } \\
\% \\
\end{array}$} & \multirow{2}{*}{$\begin{array}{c}\text { Matéria } \\
\text { orgânica } \\
\text { g kg-1 }^{-1}\end{array}$} & \multirow[b]{2}{*}{$\begin{array}{c}\mathrm{P} \\
\mathrm{mg} \mathrm{dm}\end{array}$} & \multicolumn{4}{|c|}{ Complexo sortivo } \\
\hline & & & & & & $\mathrm{Ca}^{2+}$ & $\mathrm{Mg}^{2+}$ & $\begin{array}{c}\mathrm{Na}^{+} \\
\mathrm{l}_{\mathrm{c}} \mathrm{dm}^{-3}\end{array}$ & $\mathrm{~K}^{+}$ \\
\hline Franc & renoso & 1,38 & 47,00 & 32 & 17 & 5,4 & 4,1 & 2,21 & 0,28 \\
\hline \multicolumn{10}{|c|}{ Extrato de saturação } \\
\hline pHes & $\begin{array}{c}\mathrm{CE}_{\mathrm{es}} \\
\mathrm{dS} \mathrm{m}^{-1}\end{array}$ & $\mathrm{Ca}^{2+}$ & $\mathrm{K}^{+}$ & $\begin{array}{c}\mathrm{Na}^{+} \mathrm{Cl}^{-} \\
---\mathrm{mmol}_{\mathrm{c}} \mathrm{dm}^{-}\end{array}$ & $\mathrm{SO}_{4}{ }^{2-}$ & $\mathrm{CO}_{3}{ }^{2-}$ & $\mathrm{HCO}_{3}^{-}$ & \multicolumn{2}{|c|}{$\begin{array}{c}\text { Saturação } \\
\%\end{array}$} \\
\hline 7,41 & 1,21 & 2,50 & 4,74 & $3,02 \quad 7,50$ & 3,10 & 0,00 & 5,63 & \multicolumn{2}{|c|}{27,00} \\
\hline
\end{tabular}


Foi utilizado no experimento a aceroleira 'CMI 102', proveniente da Embrapa Mandioca e Fruticultura - Cruz das Almas - BA. Após as plântulas apresentarem dois pares de folhas verdadeiras totalmente expandidas, realizou-se o desbaste, deixando-se apenas uma plântula por sacola, a de melhor vigor. Também foi realizado tratos culturais durante 0 desenvolvimento das plantas, como arranquio de plantas invasoras e escarificação superficial do substrato para remoção de camadas compactadas.

Durante o período experimental, o solo foi mantido com umidade próxima da capacidade de campo, sendo que, nos primeiros 30 dias após a emergência (DAE), as plântulas foram irrigadas com água de abastecimento local $\left(0,3 \quad d S \quad \mathrm{~m}^{-1}\right) \quad$ e posteriormente passaram a receber água conforme tratamentos.

As irrigações foram feitas com base na necessidade hídrica da planta, pelo processo de lisimetria de drenagem (foram escolhidas vinte sacolas e colocado um coletor), sendo aplicado diariamente o volume retido na sacola, determinado pela diferença entre o volume aplicado e o volume drenado da irrigação anterior (BERNARDO et al., 2006), aplicadas duas vezes ao dia, sendo no início da manhã e final da tarde. A cada quinze dias, foi aplicada uma fração de lixiviação de $15 \%$ com base no volume aplicado neste período, com o propósito de reduzir o acúmulo do substrato. Estas plantas foram conduzidas até serem consideradas aptas para o transplante.

A adubação nitrogenada iniciou-se aos 30 DAE, dividida em 14 aplicações em partes iguais, realizadas semanalmente utilizando como fonte de nitrogênio a ureia ( $45 \%$ de $N)$, com aplicações realizadas via fertirrigação com água de condutividade elétrica de $0,3 \mathrm{dS} \mathrm{m}^{-1}$ para todos os tratamentos.

O crescimento das mudas de aceroleira “CMI 102" foi avaliado aos 45 e 135 DAE, através da altura de plantas (AP), diâmetro de caule (DC) e número de folhas (NF). Outrossim aos 135 DAE, mensurou-se área foliar especifica (AFE), a fitomassa fresca de caule (FFC), de folhas (FFF), e as fitomassas secas de caules (FSC), de folhas (FSF) e raízes (FSR).

A AP foi determinada medindo-se as plantas da superfície do solo até ponto de inserção do meristema apical; o DC a uma altura de $5 \mathrm{~cm}$ acima do nível do solo utilizando um paquímetro digital $(\mathrm{mm})$. A determinação do NF foi feita por contagem de folhas que apresentavam o limbo foliar totalmente expandido.

A área foliar especifica (AFE) foi mensurada aos 150 DAE conforme descrita por Benincasa (2003), de acordo com a Eq. 1.

$$
\mathrm{AFE}=\mathrm{AF} / \mathrm{FSF} \quad \mathrm{Eq} .1
$$

Em que:

$\mathrm{AFE}$ = área foliar específica, em $\mathrm{cm}^{2} \mathrm{~g}^{-1}$;

$\mathrm{AF}=$ área foliar, em $\mathrm{cm}^{2}$;

$\mathrm{FSF}=$ fitomassa seca da folha, em $\mathrm{g}$.

Para determinação do acúmulo de fitomassa fresca, cortou-se as plantas rente ao solo e, em seguida, foram separadas as distintas partes caule e folha, que foram pesadas imediatamente em balança de precisão (0,001 g), para determinação da FFC e FFF.

Após a pesagem das fitomassas frescas, as distintas partes da planta (folhas, caule e raízes) foram acondicionadas separadamente em sacos de papel devidamente identificados e postos para secar em estufa de circulação forçada de ar, mantida na temperatura de $65^{\circ} \mathrm{C}$ até obtenção de massa constante para determinação da FSF, FSC e a FSR.

Os dados foram avaliados mediante análise de variância pelo teste F (1 e 5\% de probabilidade) e no caso de efeito significativo, realizou-se análise de regressão polinomial linear e quadrática, utilizando-se do software estatístico SISVAR (FERREIRA, 2011) para ambos os fatores estudados.

\section{RESULTADOS E DISCUSSÕES}

Com base no resumo da análise de variância (Tabela 2), verifica-se efeito significativo da interação entre os fatores (salinidade da água de irrigação e doses de adubação nitrogenada) e da adubação 
nitrogenada, apenas em relação ao diâmetro do caule aos 45 DAE. Em relação aos níveis de salinidade da água de irrigação constata-se efeito significativo aos 45 dias após a emergência (DAE), sobre a altura de planta e diâmetro do caule e, aos 135 DAE para altura de planta, diâmetro de caule e número de folhas de mudas de aceroleira 'CMI 102'.

Tabela 2. Resumos das análises de variância para altura de plantas (AP), diâmetro de caule (DC) e número de folhas (NF) de mudas de aceroleira 'CMI 102', aos 45 e 135 dias após emergência sob diferentes níveis de salinidade da água de irrigação e doses de nitrogênio.

QUADRADO MÉDIO

\begin{tabular}{|c|c|c|c|c|c|c|c|}
\hline \multirow[t]{2}{*}{ Fonte de variação } & \multirow[b]{2}{*}{ GL } & \multicolumn{2}{|c|}{ AP } & \multicolumn{2}{|c|}{$\overline{\mathrm{DC}}$} & \multicolumn{2}{|c|}{ NF } \\
\hline & & 45 & 135 & 45 & 135 & 45 & 135 \\
\hline Níveis salinos (S) & 4 & $48,54^{*}$ & $847,21^{* *}$ & $1,47^{* *}$ & $1,08^{*}$ & $9,38^{\mathrm{ns}}$ & $266,07 * *$ \\
\hline Reg. Linear & 1 & $119,54^{* *}$ & $3155,06^{* *}$ & $5,72^{* *}$ & $3,83^{* *}$ & $0,15^{\mathrm{ns}}$ & $774,40^{*}$ \\
\hline Reg. Quadrática & 1 & $23,59^{\text {ns }}$ & $8,06^{\mathrm{ns}}$ & $0,005^{\text {ns }}$ & $0,28^{\mathrm{ns}}$ & $22,50^{\mathrm{ns}}$ & $77,78^{\text {ns }}$ \\
\hline Doses de N (DN) & 3 & $16,39^{\text {ns }}$ & $82,89^{\text {ns }}$ & $0,13^{* *}$ & $0,40^{\text {ns }}$ & $5,73^{\mathrm{ns}}$ & $10,58^{\text {ns }}$ \\
\hline Reg. Linear & 1 & $0,14^{\mathrm{ns}}$ & $28,62^{\text {ns }}$ & $0,39^{* *}$ & $0,39^{\mathrm{ns}}$ & $2,56^{\mathrm{ns}}$ & $13,69^{\text {ns }}$ \\
\hline Reg. Quadrática & 1 & $0,88^{\mathrm{ns}}$ & $11,25^{\text {ns }}$ & $0,001^{\text {ns }}$ & $0,05^{\mathrm{ns}}$ & $9,80^{\mathrm{ns}}$ & $18,05^{\text {ns }}$ \\
\hline Interação (S x DN) & 12 & $32,71^{\text {ns }}$ & $106,58^{\text {ns }}$ & $0,05^{*}$ & $0,81^{\mathrm{ns}}$ & $35,17^{\mathrm{ns}}$ & $45,70^{\text {ns }}$ \\
\hline Bloco & 3 & $244,03^{* *}$ & $241,67^{\mathrm{ns}}$ & $0,03^{\mathrm{ns}}$ & $5,04^{* *}$ & $1,73^{\mathrm{ns}}$ & $204,31^{\mathrm{ns}}$ \\
\hline CV (\%) & & 18,77 & 19,09 & 6,34 & 12,02 & 14,28 & 20,28 \\
\hline
\end{tabular}

ns, **, * respectivamente não significativos, significativo a p $<0,01$ e p $<0,05$;

O incremento na salinidade da água de irrigação causou efeito linear decrescente de $3,46 \%$ e $6,75 \%$ por aumento unitário na CEa sobre a AP aos 45 e 135 DAE respectivamente (Figura 1A). As plantas irrigadas com água de CEa de 4,3 dS m ${ }^{-1}$ sofreram reduções na AP de $13,84 \%(3,45 \mathrm{~cm})$ e $27,02 \%(17,75 \mathrm{~cm})$ em relação as plantas irrigadas com água de menor CEa $\left(0,3 \mathrm{dS} \mathrm{m}^{-1}\right)$. Deste modo, a redução na
AP em função dos níveis de CEa deve estar associado ao aumento da concentração de sais na solução do solo, que promove redução do potencial osmótico levando a uma maior capacidade de retenção de agua no solo, afetando a absorção e como consequência diminuição do crescimento das plantas cultivadas (GARCIA et al., 2010). 

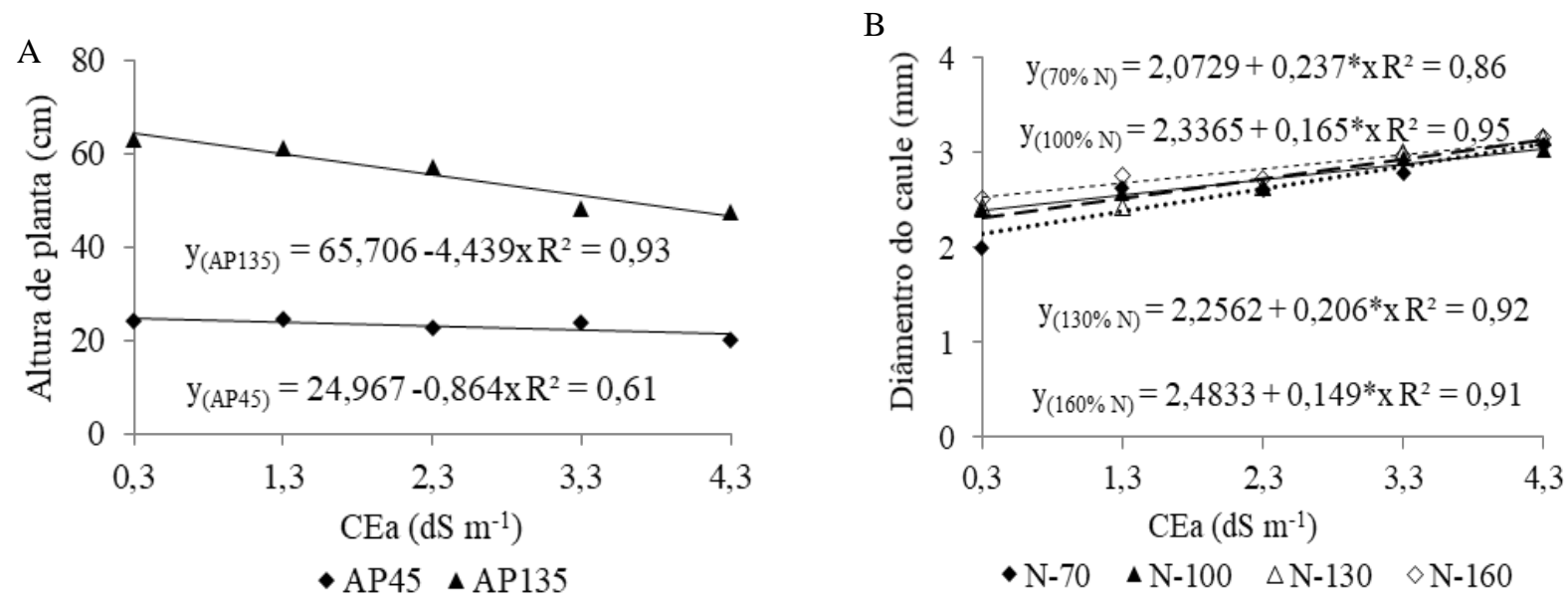

Figura 1. Altura de planta de mudas de aceroleira 'CMI 102', sob distintas salinidades da água de irrigação CEa aos 45 e 135 DAE (A) e diâmetro do caule de plantas adubadas com diferentes doses de nitrogênio em função da salinidade da água de irrigação aos 45 - DAE (B).

No desdobramento dos níveis de salinidade dentro de cada dose de $\mathrm{N}$ observase (Figura 1B), efeito linear crescente nas mudas submetidas à adubação com 70,100 , 130 e $160 \%$ de $\mathrm{N}$ cujos acréscimos foram de 11,$43 ; 7,06 ; 9,13$ e $6,0 \%$ respectivamente, por aumento unitário da CEa, correspondentes a aumentos de 45,$73 ; 28,24 ; 36,52$ e $24,0 \%$ no DC das mudas de aceroleira sob irrigação com CEa de $4,3 \mathrm{dS} \mathrm{m}^{-1}$ quando comparadas com as plantas irrigadas com água de CEa de 0,3 dS $\mathrm{m}^{-1}$. Denota-se com o resultado, que a aplicação de dose de $\mathrm{N}$ de $70 \%$ da recomendação possivelmente tenha atendido as necessidades nutricionais da cultura, contribuindo desta forma para uma resposta positiva do DC.

Desta forma, o efeito positivo do nitrogênio pode estar associado às funções do $\mathrm{N}$ no metabolismo das plantas, visto que este macronutriente faz parte de diversos compostos orgânicos vitais para o vegetal, como aminoácidos, proteínas, ácidos nucleicos, pigmentos e vários hormônios vegetais. Além disto, estudos têm demonstrado que o acúmulo deste soluto orgânico eleva a capacidade de ajustamento osmótico das plantas à salinidade (LIMA et al., 2015).

De acordo com a equação de regressão para o diâmetro do caule de mudas de aceroleira 'CMI 102' aos 135 DAE (Figura 2A), verifica-se resposta linear e decrescente com o aumento da condutividade elétrica da água de irrigação, ocorrendo redução no DC por aumento unitário da CEa de 2,55\%, ou seja, as mudas de aceroleira que receberam a maior CEa (4,3 dS m$\left.{ }^{-1}\right)$ tiveram diminuição no DC de $0,62 \mathrm{~mm}(10,20 \%)$ quando comparada com as plantas irrigadas com a menor nível salino (0,3 dS $\left.\mathrm{m}^{-1}\right)$. De acordo com Prisco; Gomes Filho (2010), essas alterações morfológicas ocorrem em razão do desbalanço hídrico, nutricional e hormonal. Souza et al. (2016) verificaram redução do diâmetro do caule de plantas de goiabeira "Crioula" submetidas a níveis crescente da condutividade elétrica da água devido a toxidez dos sais presentes na água, fato que resultará em sérios prejuízos ao crescimento, desenvolvimento, produção e produtividade dos vegetais. 
A

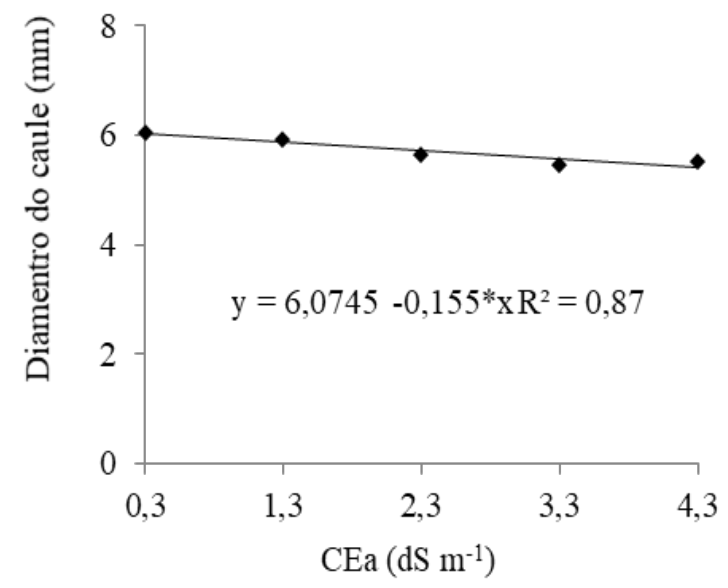

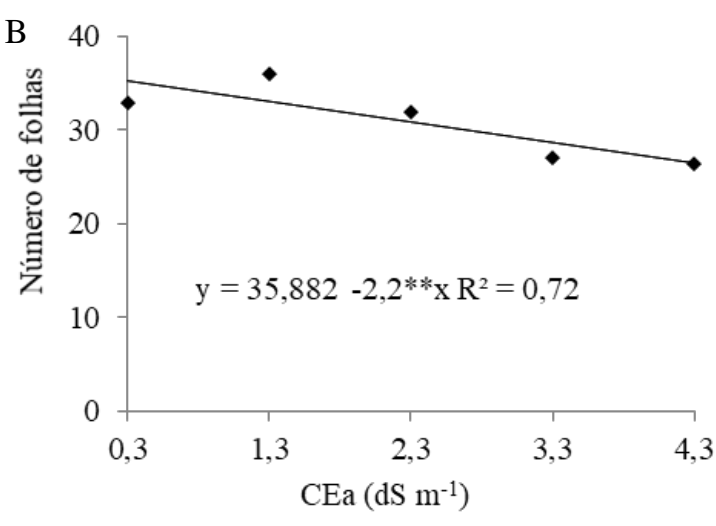

(B) de mudas de aceroleira 'CMI 102' em função da Figura 2. Diâmetro do caule (A) e Número de folh
salinidade da água de irrigação - CEa aos 135 DAE.

Verifica-se de acordo com a equação de regressão (Figura 2B) que o aumento da salinidade da água de irrigação causou redução de $6,13 \%$ no número de folhas de aceroleira por aumento unitário da CEa. Plantas submetidas a irrigação com CEa de 4,3 dS m ${ }^{-1}$ tiveram redução no NF de $24,52 \%$ quando comparada com as plantas irrigadas com água de condutividade de elétrica de $0,3 \mathrm{dS} \mathrm{m}^{-1}$. Souza et al. (2016), estudando produção de mudas de goiabeira em função da salinidade também observaram que o aumento da salinidade da água de irrigação proporcionou efeito linear decrescente para variável número de folhas aos $85 \mathrm{DAE}$, que segundo equação de regressão, a redução por aumento unitário da CEa foi de 8,35\%, ou seja, as plantas que foram irrigadas com a condutividade mais elevada
(3,5 dS $\left.\mathrm{m}^{-1}\right)$ apresentaram diminuição de 26,72\% (3,4 folhas por planta). Esta redução no número de folhas pode ser um mecanismo de adaptação das plantas ao estresse, como forma de minimizar as perdas de água por transpiração (SOARES et al., 2012).

Observa-se (Tabela 3), que houve efeito significativo dos níveis salinos da água de irrigação sobre área foliar especifica aos 135 dias após a emergência (DAE) e sobre a fitomassas frescas e secas de folhas e caule e, seca de raiz de mudas aceroleira 'CMI 102'. Não foi constatada interação significativa entre salinidade da água de irrigação e doses de nitrogênio ( $\mathrm{S} \times \mathrm{DN}$ ) assim como, do fator adubação nitrogenada em nenhuma variável estudada.

Tabela 3. Resumos das análises de variâncias para área foliar especifica (AFE), fitomassa fresca da folha (FFF) e caule (FFC), fitomassa seca de folha (FSF) e caule (FSC), e fitomassa seca da raiz (FSR) de mudas de aceroleira 'CMI 102', aos 135 dias após emergência sob diferentes níveis de salinidade da água de irrigação e doses de nitrogênio.

QUADRADOS MÉDIOS

\begin{tabular}{lccccccc} 
Fonte de variação & GL & AFE & FFF & FFC & FSF & FSC & FSR \\
\hline Níveis salinos (S) & 4 & $23567,5^{*}$ & $7,32^{* *}$ & $69,82^{* *}$ & $69,82^{* *}$ & $2,78^{* *}$ & $0,26^{*}$ \\
Reg. Linear & 1 & $27696,5^{*}$ & $24,20^{* *}$ & $41,60^{* *}$ & $41,60^{* *}$ & $7,71^{* *}$ & $0,73^{* *}$ \\
Reg. Quadrática & 1 & $20237,6^{* *}$ & $0,66^{\text {ns }}$ & $10,99^{*}$ & $10,99^{*}$ & $100^{\text {ns }}$ & $0,02^{\text {ns }}$ \\
Doses de N (DN) & 3 & $3482,2^{\text {ns }}$ & $2,65^{\text {ns }}$ & $1,62^{\text {ns }}$ & $1,62^{\text {ns }}$ & $0,20^{\text {ns }}$ & $0,0008^{\text {ns }}$
\end{tabular}




\begin{tabular}{|c|c|c|c|c|c|c|c|}
\hline Reg. Linear & 1 & $1494,6^{\mathrm{ns}}$ & $3,64^{\mathrm{ns}}$ & $2,62^{\mathrm{ns}}$ & $2,62^{\mathrm{ns}}$ & $0,46^{\mathrm{ns}}$ & $0,0005^{\mathrm{ns}}$ \\
\hline Reg. Quadrática & 1 & $7976,0^{\text {ns }}$ & $0,15^{\mathrm{ns}}$ & $2,18^{\text {ns }}$ & $2,18^{\mathrm{ns}}$ & $0,005^{\mathrm{ns}}$ & $0,0001^{\mathrm{ns}}$ \\
\hline Interação (S x DN) & 12 & $8730,7^{\mathrm{ns}}$ & $2,25^{\mathrm{ns}}$ & $2,70^{\mathrm{ns}}$ & $2,70^{\mathrm{ns}}$ & $0,61^{\mathrm{ns}}$ & $0,17^{\mathrm{ns}}$ \\
\hline Bloco & 3 & $7882,3^{\text {ns }}$ & $14,07^{* *}$ & $22,76^{* *}$ & $22,76^{* *}$ & $4,62^{\mathrm{ns}}$ & $1,40^{* *}$ \\
\hline CV (\%) & & 20,04 & 19,82 & 18,06 & 15,06 & 16,32 & 15,57 \\
\hline
\end{tabular}

O aumento da CEa afetou de forma negativa a fitomassa fresca e seca de folhas de aceroleira e, de acordo com as equações de regressão (Figura 3A e B), nota-se declínio, de $7,21 \%$ e $9,57 \%$ respectivamente por aumento unitário da CEa, isto equivale a uma redução de $28,84 \%$ (FFF) e $38,28 \%$ (FSF), das plantas irrigadas com água de $4,3 \mathrm{dS} \mathrm{m}^{-1}$ quando comparado com as sob CEa de $0,3 \mathrm{dS} \mathrm{m}^{-1}$. Essa diminuição na fitomassa sob condições de estresse salino, certamente está atribuída ao fato da planta, com o intuito de se ajustar osmoticamente, desprender determinada quantidade de energia para acumulação de açúcares, ácidos orgânicos e íons no vacúolo, energia que poderia ser utilizada no acúmulo de fitomassa (SANTOS et al., 2012).
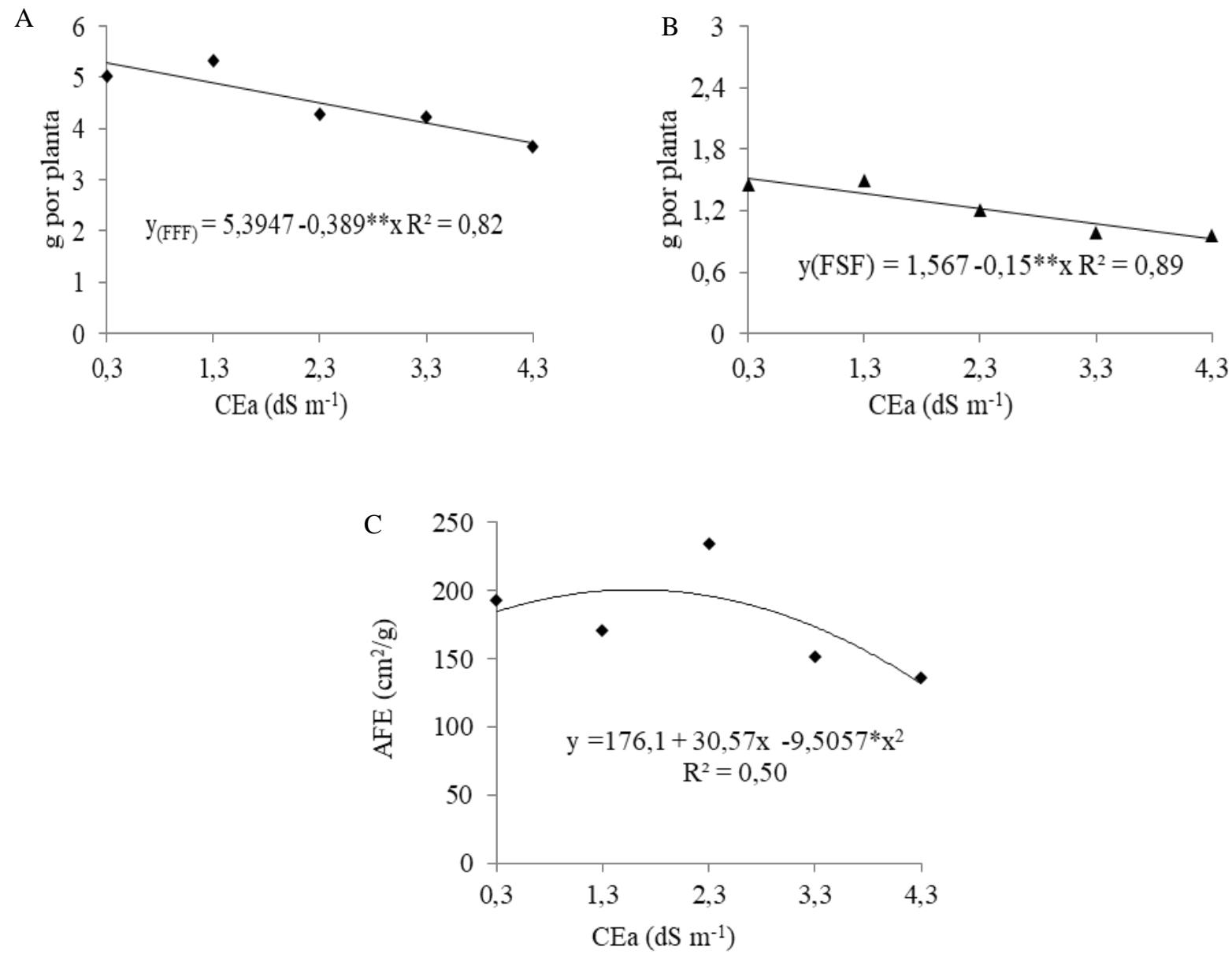

Figura 3. fitomassa fresca de folhas (A), seca de folhas (B) e área foliar especifica (A) de mudas de aceroleira 'CMI 102' em função da salinidade da água de irrigação aos 135 DAE. 


\section{ADUBAÇÃO NITROGENADA}

Observa-se que o aumento da salinidade na água de irrigação proporcionou efeito quadrático sobre a AFE aos 135 DAE (Figura 3C), segundo equação de regressão, o maior valor de $200,67 \mathrm{~g} / \mathrm{cm}^{2}$ foi atingido nas plantas irrigadas no nível de CEa de 1,6 dS $\mathrm{m}^{-1}$. Valores similares foi encontrado em trabalho realizado por Sena et al. (2018), estudando produção de porta-enxerto de goiabeira irrigada com aguas salinas, onde verificou-se decréscimo na ordem de 5,66\% (80 DAT) e 7,78\% (170 DAT), por aumento unitário da CEa. Plantas quando submetidas à $\mathrm{CEa}$ de $3,5 \mathrm{dS}$ m-1 reduziram $18,12 \%$ e $24,92 \%$, respectivamente, sob CEa de $0,3 \mathrm{dS}$ m-1. A redução na área foliar representa um mecanismo de defesa das plantas sob condições de estresse hídrico e salino, reduzindo as perdas de água por transpiração (TAIZ; ZEIGER, 2013).

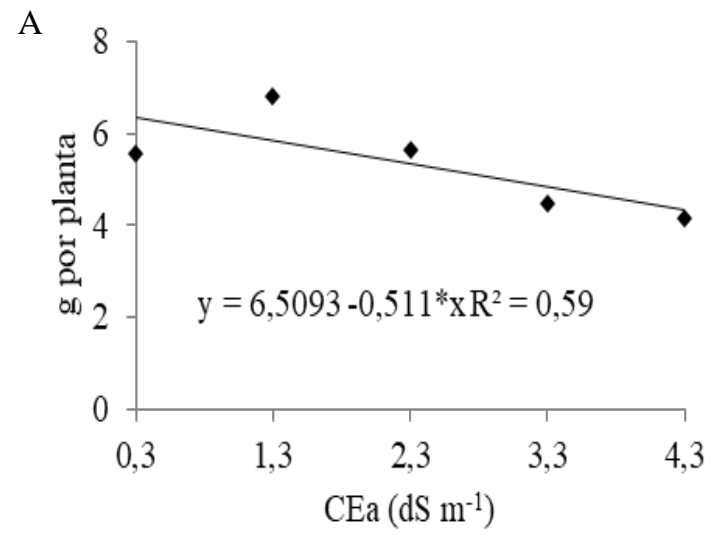

Nota-se que a salinidade da água causou efeitos deletérios sobre a FFC e FSC aos 135 DAE (Figura 4A e B), ocorrendo segundo as equações de regressão, comportamento linear e decrescente de $7,85 \%$ e $8,40 \%$ respectivamente por aumento unitário na CEa. As plantas submetidas a CEa de 4,3 dS m${ }^{-1}$ apresentaram diminuição na produção de FFC de $31,40 \%$ (2,04 g por planta) e na FSC de $33,61 \% \quad(0,87 \mathrm{~g}$ por planta $)$ quando comparadas as que receberam irrigação com CEa de $0,3 \mathrm{dS} \mathrm{m}^{-1}$. A redução no acúmulo de biomassa é consequência de estresse salino e/ou hídrico onde as plantas na tentativa de ajustamento às condições adversas do estresse, incluindo modificações no balanço iônico, potencial hídrico, nutrição mineral, fechamento estomático, eficiência fotossintética e alocação de carbono (TAIZ; ZEIGER, 2013) tendem a apresentar menor crescimento.

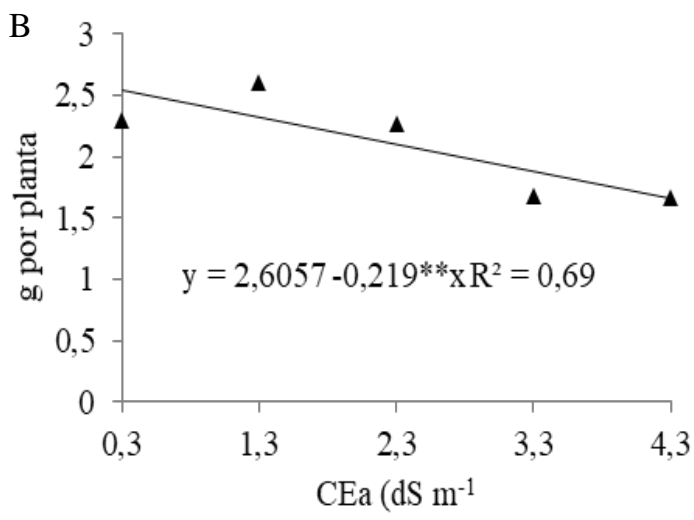

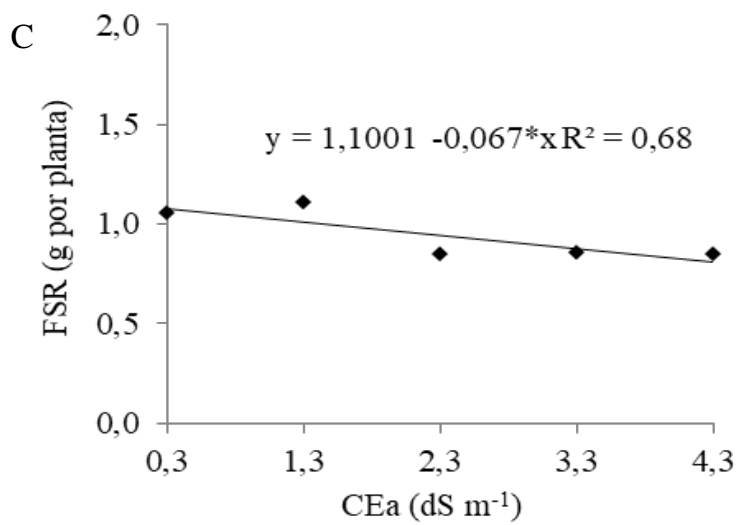

Figura 4. Fitomassa fresca de caule (A), seca de caule (B) e seca de raiz (C) de mudas de aceroleira em função da salinidade da água de irrigação aos 135 dias após a emergência - DAE. 
Verifica-se, aos 135 DAE, que apenas o fator salinidade da água afetou produção de FSR (Tabela 3) em que, conforme a equação de regressão (Figura 4C), o modelo ao qual os dados se ajustaram melhor foi o linear, indicando decréscimo do FSR de 6,63\% por aumento unitário da CEa, ou seja, redução de $25,44 \%$ na FSR das mudas de aceroleira irrigadas com água de $4,3 \mathrm{dS} \mathrm{m}^{-1}$ em relação às submetidas a $0,3 \mathrm{dS} \mathrm{m}^{-1}$. Em meio salino a redução no consumo de água em função do aumento da pressão osmótica reduzindo a absorção de nutrientes e águas pelas plantas, e desta forma, o crescimento, desenvolvimento e produção de fitomassa da planta pode ser diretamente afetada (ABRANTES et al., 2017).

Guimarães et al. (2013), relatam que as raízes são altamente suscetíveis ao estresse salino, especialmente, pelo fato da ação deletéria dos sais resultar em considerável decréscimo em sua biomassa seca, visto que, o crescimento radicular é determinado por uma alta atividade metabólica, aliado ao fato de que a raiz é o único órgão diretamente exposto ao excesso de sais no solo, neste caso, a medida em que aumentou-se a CEa, houve incremento no estresse e assim, as atividades metabólicas diminuem e as plantas tendem a produzir menos fitomassa.

\section{CONCLUSÕES}

$\mathrm{Na}$ formação de mudas de aceroleira "CMI 102", pode ser utilizada água com CEa de 1,88 dS $\mathrm{m}^{-1}$, pois promove redução média aceitável de $10 \%$ no crescimento das mudas.

O aumento na salinidade da água de irrigação reduz o crescimento de mudas de aceroleira “CMI 102", principalmente aos 135 DAE.

Doses de adubação nitrogenada de 420 mg de $\mathrm{N} \mathrm{dm}^{-3}$ proporcionou aumento do diâmetro do caule em interação com o aumento da salinidade da água de irrigação.

\section{REFERÊNCIAS BIBLIOGRÁFICAS}

ABRANTES, D. F.; NOBRE, R. G.; SOUZA, L. P.; GOMES, E. M.; SOUZA, A. S.; SOUSA, F. F. Produção de mudas enxertadas de goiabeira irrigadas com águas salinizadas sob adubação nitrogenada. Revista Espacios, vol. 38, n. 31, p. 6, 2017

ADRIANO, E.; LEONEL, S.; EVANGELISTA, R. M. Qualidade de fruto da aceroleira cv. Olivier em dois estádios de maturação. Revista Brasileira Fruticultura, v. 33, n.1, p. 541-545, 2011.

ALVES, M. S.; SOARES, T. M.; SILVA, L. T.; FERNANDES, J. P.; OLIVEIRA, M. L. A.; PAZ, V. P. S. Estratégias de uso de água salobra na produção de alface em hidroponia NFT. Revista Brasileira de Engenharia Agrícola e Ambiental, v.15, n.5, p. 491-498, 2011.

BENINCASA, M. M. P. Análise de crescimento de plantas, noções básicas. FUNEP, Jaboticabal: 41 p. 2003.

BERNARDO, S.; SOARES, A. A.; MANTOVANI, E. C. Manual de irrigação. UFV, Viçosa: 8 ed. 625 p. 2006.

BEZERRA, A. K. P.; LACERDA, C. F. de; HERNANDEZ, F. F. F.; SILVA, F. B. da; GHEYI, H. R. Rotação cultural feijão caupi/milho utilizando-se águas de salinidades diferentes. Revista Ciência Rural, v.40, n.5, p.1075-1082. 2010.

BLANCO, F.F., FOLEGATTI, M.V., HENRIQUES NETO, D. 2008. Doses de N e $\mathrm{K}$ no tomateiro sob estresse salino: $\mathrm{I}$. Concentração de nutrientes no solo e na planta. Revista Brasileira de Engenharia Agrícola e Ambiental v.12, n.1, p.26-33, 2008.

BRUNINI, M. A.; MACEDO, N. B.; COELHO, C. V.; SIQUEIRA, G. F. Caracterização física e química de acerolas provenientes de diferentes regiões de cultivo. 
Revista Brasileira de Fruticultura, v.26, n.3, p.486-489, 2007.

CLAESSEN, M. E. C. (1997). Manual de métodos de análise de solo (2nd ed.). Rio de Janeiro, RJ: Embrapa CNPS.

FERREIRA, D. F. SISVAR. A computer statistical analysis system. Ciência e Agrotecnologia v.35, n.6, p.1039-1042, 2011.

FERREIRA, K. S. Crescimento e acúmulo de nutrientes em mudas de aceroleira adubadas com nitrogênio e potássio. 2014. 50 f. (Dissertação mestrado em ciências agrárias) Universidade Federal de São João Del Rei.

GARCIA, G. de O.; NAZÁRIO, A.A.; MORAES, W.B.; GONÇALVES, I.Z.; MADALÃO, J.C. Respostas de genótipos de feijoeiro à salinidade, Engenharia na Agricultura, v.18, n.2, p.120 - 139, 2010.

GUIMARÃES, I. P.; OLIVEIRA, F. N.; VIEIRA, F. E. R.; TORRES, S. B. Efeito da salinidade da água de irrigação na emergência e crescimento inicial de plântulas de mulungu. Revista Brasileira de Ciências Agrárias, v.8, n.1, 137 - 142, 2013.

LACERDA, C. F, SOUSA. G. G, SILVA, F. L. B, GUIMARÃES, F. V. A, SILVA, G. L, CAVALCANTE, L. F. Soil salinization and maize and cowpea yield in the crop rotation system using saline waters. Engenharia Agrícola, v.31, n.1, p.663-675, 2011.

LIMA, L. A.; OLIVEIRA, F DE A.; ALVES. R DE C.; LINHARES. P. S. F.; MEDEIROS. A. M. A DE.; BEZERRA. F. M. S. Tolerância da berinjela à salinidade da água de irrigação. Revista Agroambiente, v.9, n.2, p.27-34, 2015.

MEDEIROS, J. F. Qualidade da água de irrigação e evolução da salinidade nas propriedades assistidas pelo "GAT" nós Estado do RN, PB e CE. 1992. 173 f. (Dissertação Mestrado em Engenharia
Agrícola) - Programa de Pós-Graduação, Universidade Federal da Paraíba, Campina Grande.

NOBRE, G R.; SOARES DE LIMA, G.; RAJ GHEYI, H.; DA SILVA LOURENÇO, G.; ALMEIDA DOS ANJOS SOARES, L. Emergência, crescimento e produção da mamoneira sob estresse salino e adubação nitrogenada. Revista Ciência Agronômica, Fortaleza. V. 44, n. 3, 2013.

PÁDUA, L. S.; NOBRE, R. G.; SILVA, E. M.; GHEYI, H. R.; SOARES, L. A. dos A.; Produção de porta-enxerto de goiabeira cultivado com águas de diferentes salinidades e doses de nitrogênio, Revista Ciência Agronômica, v. 48, n. 4, p. 596-604, 2017.

PRISCO, J. T.; GOMES FILHO, E. Fisiologia e bioquímica do estrese salino em plantas. In: GHEYI, H. R,; DIAS, N. S.; LACERDA, C. F. (ed.) Manejo da salinidade na agricultura: Estudos básicos e aplicados. Fortaleza. INCT. 2010. Cap. 10. P. 147-164.

ROZANE, D. E.; PRADO, R. M.; FRANCO, C. F.; NATALE, W. Eficiência de absorção, transporte e utilização de macronutrientes por porta-enxerto de caramboleira, cultivados em soluções nutritivas. Ciência e Agrotecnologia v.31, n.1, p.1020-1026, 2007.

SANTOS, D. B.; FERREIRA, P. A.; OLIVEIRA, F. G. de; BATISTA, R. O.; COSTA, A. C.; CANO, M. A. O. Produção e parâmetros fisiológicos do amendoim em função do estresse salino. Idesia v.30, n.2, p.69-74, 2012.

SENA, G. S. A. DE.; NOBRE, R. G.; SOUZA, L. DE P.; ARAÚJO, S. C. A.; SILVA, I. A. DA. Crescimento de porta-enxerto de goiabeira cv. paluma irrigada com águas salinas e adubação nitrogenada. Revista Engenharia na Agricultura, v.26, n.02, p.190-199, 2018.

SILVA, E. C.; NOGUEIRA, R. J. M. C.; ARAÚJO, F. P.; MELO, N. F.; AZEVEDO 
NETO, A. D. Physiological responses to salt stress in young umbu plants. Environmental and Experimental Botany, v.63, n.1-3, p.147-157, 2008.

SOARES, L. A. dos A.; NOBRE, R. G.; GHEYI, H. R.; de LIMA, G. S. da SILVA, A. O.; SOARES, S. da S. Componentes de crescimento da mamoneira cultivada com águas salinas e doses de nitrogênio. Irriga v.1, n.2, p.40-54, 2012.
SOUZA, L. DE P.; REGINALDO G. N.; EVANDRO M. DA S.; GEOVANI S. DE L.; PINHEIRO. F. W. A.; ALMEIDA. L. L. DE S. Formation of 'Crioula' guava rootstock under saline water irrigation and nitrogen doses. Revista Brasileira de Engenharia Agrícola e Ambiental v.20, n.1, p.739-745, 2016.

TAIZ, L.; ZEIGER, E. Fisiologia vegetal. 5. Ed. ArtMed , Porto Alegre, Brasil, 2013. 954 p. 